\title{
Avaliação em Matemática: algumas considerações
}

\author{
REGINA MARIA PAVANELLO \\ Professora do Programa de Pós-graduação em Educação para a Ciência e o Ensino \\ da Matemática da Universidade Estadual de Maringá \\ reginapavanello@hotmail.com \\ CLÉLIA MARIA IGNATIUS NOGUEIRA \\ Professora do Programa de Pós-graduação em Educação para a Ciência e o Ensino \\ da Matemática da Universidade Estadual de Maringá \\ clelia@wnet.com.br
}

\begin{abstract}
Resumo
O objetivo deste texto é discutir a trajetória a ser considerada quando se pensa na avaliação em matemática. Assim, partimos da constatação de que há diferentes modos de conceber a matemática, paradigmas que se filiam a sistemas filosóficos existentes desde a Antiguidade. Esses paradigmas, por sua vez, influenciam o fazer matemática, o fazer pedagógico em matemática e, por conseguinte, a avaliação.

Palavras-chave: educação matemática, concepções de matemática, avaliação em matemática.
\end{abstract}

\section{Resumen}

El objetivo de este texto es discutir la trayectoria a ser considerada cuando se piensa en el acto de evaluar en matemática. Así, partimos de la constatación de que hay diferentes modos de concebir la matemática, paradigmas que se afilian a sistemas filosóficos que existen desde la Antigüedad. Estos paradigmas, a su vez, influencian el hacer matemática, el hacer pedagógico en matemática $\mathrm{y}$, por consiguiente, la evaluación en matemática.

Palabras-clave: educación matemática, concepciones de matemática, evaluación en matemática.

\begin{abstract}
The aim of this paper is to discuss the path to be taken when evaluation in mathematics is considered. In order to do so, we start from the fact that there are different ways of conceiving mathematics, paradigms which are linked to philosophical systems dating back to Antiquity. These paradigms influence the ways of doing mathematics, doing pedagogy in mathematics and, therefore, evaluation in mathematics.

Key words: mathematical education, conception of mathematics, evaluation in mathematics.
\end{abstract}




\section{PENSANDO SOBRE AVALIAÇÃO}

Se há um ponto de convergência nos estudos sobre a avaliação escolar é o de que ela é essencial à prática educativa e indissociável desta, uma vez que é por meio dela que o professor pode acompanhar se o progresso de seus alunos está ocorrendo de acordo com suas expectativas ou se há necessidade de repensar sua ação pedagógica. Quanto ao aluno, a avaliação permite que ele saiba como está seu desempenho do ponto de vista do professor, bem como se existem lacunas no seu aprendizado às quais ele precisa estar atento.

O consenso termina, todavia, quando se define a avaliação, quando se abordam as maneiras de avaliar e com que níveis de exigência. Assim, como bem aponta Zabala (1998, p. 195),

... é possivel encontrar definições de avaliação bastante diferentes e, em muitos casos, bastante ambíguas, cujos sujeitos e objetos de estudo aparecem de maneira confusa e indeterminada. Em alguns casos, o sujeito da avaliação é o aluno; em outros, é o grupo/classe, ou inclusive o professor ou professora, ou a equipe docente. Quanto ao objeto da avaliação, às vezes, é o processo de aprendizagem seguido pelo aluno ou os resultados obtidos, enquanto outras vezes se desloca para a própria intervenção do professor.

Não pretendemos, neste texto, acrescentar mais polêmica às questões que envolvem a avaliação escolar, mas focar nossas reflexões principalmente em o que avaliar em matemática, independentemente do nível de ensino a que estejamos nos referindo. É evidente que, ao se pensar sobre o que é avaliar, passa-se, necessariamente, pelo o que ensinar, que depende do por que ensinar, do para quem ensinar e, portanto, do como ensinar, determinando, assim, uma trajetória que deve ser percorrida quando queremos considerar o que avaliar em matemática.

As decisões sobre o que avaliar estão alicerçadas na concepção que se tem de matemática - e suas conseqüentes implicações pedagógicas concepção esta que não é única. Dessa forma, nossa discussão inicial será a respeito dessas possíveis concepções sobre a matemática.

\section{AS DIFERENTES FORMAS DE CONCEBER A MATEMÁTICA}

Caraça (1989), em obra basilar para a compreensão da natureza do conhecimento matemático, indica a existência de duas formas de concebêlo. A primeira, a concepção mais freqüente entre os matemáticos de 
profissão, é a da matemática como um conhecimento pronto, acabado, apresentando-se, portanto, como um todo harmonioso, os diferentes assuntos se encadeando logicamente e sendo desenvolvidos progressiva e ordenadamente, de tal forma que se tem "a impressão de que, a partir das definições enunciadas, os resultados desejados decorrem infalivelmente de um processo puramente mecânico" (Davis, Hersh, 1985, p. 63). Empregando-se o termo paradigma, conforme utilizado por Kuhn (1981), poder-se-ia dizer que o paradigma predominante, entre eles, é o de uma matemática agregativa, auto-suficiente e abstrata. O que é um paradoxo, pois, mais do que ninguém, o matemático sabe que não apresenta seus resultados tal como os obteve, porque para tornar o saber comunicável precisa reorganizá-lo, dando-lhe uma forma descontextualizada, despersonalizada e atemporal (Brousseau, 1996); enfim, a mais geral possível. Essa forma mais geral possível é descrita magistralmente por Davis e Hersh (1985, p.63) quando dizem que os escritos matemáticos "seguem uma convenção inquebrantável: esconder qualquer vestígio de que o autor ou o leitor ao qual se dirige são seres humanos".

A outra maneira de conceber a matemática, segundo Caraça, é procurar entender como esse conhecimento foi elaborado no decorrer da História e o que influenciou tal elaboração. Esse é o ponto de vista adotado, também, por Gonzalez (1997) quando assinala ser a natureza dessa disciplina histórica, ou seja, seu grau de desenvolvimento e de evolução em uma determinada época é o reflexo das interações dialéticas entre as diversas forças econômicas, políticas e sociais vigentes nesse período. Dessa forma, o estágio atual da matemática seria resultante de um lento e prolongado processo histórico-social, e o modo como os sistemas matemáticos se apresentam hoje seria conseqüência do trabalho de diversas gerações de matemáticos, ao longo dos diferentes períodos históricos.

Encarada segundo este novo paradigma, a elaboração do conhecimento matemático configura-se, então, como um processo não unicamente cumulativo, uma vez que nela se descobrem hesitações, dúvidas e contradições, eliminadas somente após um árduo trabalho de reflexão e refinamento, muitas vezes seguido pelo surgimento de novas hesitações, dúvidas e contradições.

Assumindo esse novo paradigma, torna-se evidente que $o$ conhecimento matemático não é auto-suficiente, isto é, não evolui unicamente em razão de necessidades internas, mas também de problemas impostos pelo meio social e pelo desenvolvimento de outros campos do conhecimento. Além disso, embora a apresentação final dos resultados seja feita sob a forma demonstrativa, não é possível ignorar ou minimizar o 
papel da suposição, da conjectura, na elaboração do conhecimento matemático (Pavanello, 1993).

É importante observar que a concepção do pesquisador, do autor de um texto ou do professor acerca da matemática vai se refletir nas suas decisões sobre o que é fazer matemática, sobre por que e como ensinar/aprender, e, evidentemente, sobre o que ensinar e o que avaliar em matemática.

\section{FAZER MATEMÁTICA}

Optando-se pelo primeiro dos paradigmas anteriormente descritos, concebe-se a matemática como um produto e, portanto, o fazer matemática tem como objetivo o seu avanço enquanto ciência, atrelado à busca de novos resultados nesse campo do conhecimento.

Já o segundo paradigma leva a uma concepção da matemática como uma síntese dialética processo-produto (Gonzalez, 1997), que considera que esta ciência "nunca está pronta, acabada; nenhuma formalização fica estabelecida de uma vez por todas. Uma definição, um conceito serão enunciados cada vez mais precisamente, à medida que forem necessários à resolução de problemas mais e mais complexos" (Pavanello, 1993).

Concebe-se, dessa forma, a matemática constituída, tanto pelos próprios meios de produção do conhecimento (conjecturar, intuir, representar, estimar, simular, modelar, propor e resolver problemas) como pelos resultados desse processo (conceitos, regras, princípios, algoritmos, teoremas). Deriva dessa opção conceber-se o fazer matemática como realizar atividades lógico-matemáticas que permitam estabelecer relações matemáticas em situações que surgem da realidade em que se está inserido.

\section{POR QUE ENSINAR MATEMÁTICA}

Uma pesquisa sobre quais seriam as razões para que a matemática faça parte do currículo escolar levará certamente a três categorias de respostas. Para alguns, a função da matemática é desenvolver o raciocínio; para outros, a matemática precisa ser ensinada e aprendida porque está presente na vida cotidiana e, por último, porque ela é ferramenta para as demais ciências.

É importante observar que as razões para a inclusão da matemática no currículo escolar não são aleatórias, nem invenções recentes, mas decorrem dos paradigmas já citados, os quais, por sua vez, estão 
umbilicalmente ligados a correntes filosóficas que remontam à Antiguidade.

A crença de que a matemática desenvolve o raciocínio lógico filia-se ao primeiro paradigma e se sustenta filosoficamente nas idéias de Platão (427347 a.C.), para quem o mundo real não se constituiria senão de aparências. Para ele existiria um mundo das Formas ou Idéias onde estariam os modelos ideais dos objetos do mundo físico ou das situações que o homem deveria se esforçar para alcançar. Assim, por exemplo, nesse mundo ideal existiria a idéia de "cadeira"; enquanto as cadeiras que existem em nosso mundo seriam cópias ou representações imperfeitas daquela idéia. Nesse mundo ideal existiriam também as formas aritméticas e as geométricas. Do ponto de vista platônico, a matemática trataria apenas de objetos do mundo das idéias, e o trabalho do matemático seria o de "descobrir" as relações já existentes entre os objetos do mundo ideal.

A justificativa de que a matemática está presente no cotidiano e tem aplicações na vida prática, fundamenta-se nas idéias de Aristóteles (384-322 a.C.), cujo ponto de vista se contrapõe ao de Platão, por considerar que a matemática seria constituída de construções elaboradas pelos matemáticos a partir da percepção dos objetos do mundo real. Dessa forma, as verdades matemáticas poderiam ser comprovadas mediante experiências no mundo real.

A matemática, como ferramenta para as outras ciências, baseia-se nas idéias de Descartes (1596-1650), para quem a matemática era condição para o desenvolvimento de qualquer ramo do conhecimento, de tal modo que sem a matemática as demais ciências não seriam possíveis.

Tais justificativas para a presença da matemática nos currículos escolares podem ser sintetizadas em dois aspectos, igualmente importantes, apontados como objetivos da matemática escolar: "ser parte da educação geral, preparando o indivíduo para a cidadania, e servir de base para uma carreira em ciência e tecnologia" (D'Ambrósio, 2004). Ou como diz Santaló (1996, p.15): "a matemática tem um valor formativo que ajuda a estruturar todo o pensamento e agilizar o raciocínio dedutivo, porém é uma ferramenta que serve para a atuação diária e para muitas tarefas específicas de todas as atividades laborais".

Desse modo, parafraseando este último autor, o objetivo do ensinar/aprender matemática estaria na procura do equilíbrio constante entre os aspectos formativo e informativo da matemática. 


\section{ENSINAR/APRENDER MATEMÁTICA}

Ao se conceber a matemática como pronta, acabada, perfeita, com uma estrutura formal que serve de modelo para as demais ciências, considera-se a matemática como axiomática, isto é, logicamente deduzida a partir de um conjunto de afirmações admitidas universalmente como verdadeiras, mesmo sem demonstração - os axiomas.

Sob este ponto de vista, quem faz matemática é o matemático e o ensinar/aprender matemática se reduz à transmissão desse conhecimento para os alunos pelo professor, e a aprendizagem se faria por recepção.

Para os defensores dessa concepção, seria possível fazer com que o aprendiz construísse um pensamento simbólico sem o apoio da realidade. Ao compreender as deduções lógicas, presentes na construção da matemática, ele estaria desenvolvendo o raciocínio, objetivo final da matemática escolar. Assim, de acordo com o primeiro paradigma, o ensino da matemática não necessitaria de atividades contextualizadas. Bastaria a apresentação pelo professor das definições, dos exemplos, teoremas e exercícios-padrão e o aprendiz os aprenderia, por repetição, até compreender (ou memorizar) os raciocínios envolvidos e ser capaz de reproduzi-los.

Essa forma de conceber o processo de ensinar/aprender deixa para o aluno toda a responsabilidade pelo estabelecimento das conexões entre os diferentes ramos da matemática e entre esta e as demais disciplinas sem, contudo, lhe oferecer o preparo necessário para se desincumbir dessa tarefa. O que cabe ao aprendiz é "seguir a receita", pois raramente é convidado a pensar sobre uma questão, a discuti-la com os colegas, a estabelecer conjecturas, a testá-las.

Quando se considera a matemática como uma elaboração humana, realizada a partir de necessidades impostas pela realidade num determinado contexto histórico e social, o processo de ensinar/aprender matemática passa a ser concebido como aquele no qual o aprendiz constrói o conhecimento a partir de sua própria atividade cognoscitiva, atividade esta que se apóia nos conteúdos. Nesse sentido, o objetivo fundamental desse processo é garantir que o aprendiz elabore, desenvolva e construa estratégias que lhe permitam enfrentar novas situações-problema. Para os defensores desse paradigma, a aprendizagem da matemática deveria partir sempre de situações contextualizadas, sejam estas internas ou externas a ela.

A nosso ver, o mais adequado seria uma postura intermediária: a matemática não está apenas na mente do homem e nem apenas no mundo e seu ensino deve ser tal que, partindo daquilo que é observável, isto é, de 
situações problema contextualizadas, conduza o pensamento do aprendiz, paulatinamente, às abstrações características da matemática. Porque, apesar de ter sua origem nas coisas do mundo concreto, a matemática é constituída essencialmente de abstrações e generalizações.

\section{MATEMÁTICA ESCOLAR: INFORMAR E FORMAR}

Para complementar o percurso teórico que fizemos até aqui faltanos indicar a quem é prescrito o ensino da matemática.

A opção por uma posição intermediária entre os dois paradigmas apresentados fundamenta-se na crença de que é essencial desenvolver o pensamento do aprendiz e, ao mesmo tempo, subsidiá-lo para o exercício da sua cidadania, pois, como ressalta Santaló (1996), "a vida é pensamento e é ação, exige raciocinar para dirigir as aplicações e exige atuar para não perder-se em virtuosismos ideais, afastados da realidade em torno".

E isso se aplica a todos os indivíduos, não importa a sociedade em que estejam inseridos. Por isso, acreditamos, apoiadas em Freudenthal (1981), que as idéias matemáticas devem estar ao alcance não só dos futuros matemáticos como daqueles que, de algum modo, dela irão se utilizar. "Mesmo aqueles que dela não terão necessidade em sua vida futura (se é que isso é possível) têm direito de aprendê-la por ela representar um aspecto de sua existência como seres humanos" (Pavanello, 1993, p.12).

Pensando dessa forma, nos reportamos a Santaló (1996, p.15) que distingue a matemática que ele chama de formativa - aquela que ajuda a estruturar o pensamento e a agilizar o raciocínio dedutivo - da informativa - a que serve de ferramenta para "a atuação diária e para muitas tarefas específicas de quase todas as atividades laborais".

Em termos de conteúdos, a matemática informativa para todos deve abordar, por exemplo, porcentagens, funções e gráficos, a interpretação e confecção de tabelas, a exploração do raciocínio combinatório e do probabilístico, o cálculo aritmético, grandezas e medidas, etc., que são conteúdos essenciais para a compreensão do mundo em que vivemos. O que abordar além desses conteúdos da matemática informativa vai depender das necessidades futuras do aprendiz e do momento histórico.

É inegável que toda informação tem um substrato formativo, mas o afloramento dessa formação depende da maneira como se proporciona o acesso a essa informação. Assim, a diferença entre a matemática formativa e a informativa não está no rol de conteúdos, mas na forma de tratá-los em sala de aula. 
A escola tem-se concentrado tradicionalmente na matemática informativa, isto é, nos conhecimentos ou saberes, visando apenas aos objetivos específicos para cada conteúdo previsto nos programas de ensino. Quando nos referimos à matemática formativa, estamos propondo focar nossa atenção no desenvolvimento do pensamento, que embora não esteja desvinculado dos conteúdos não se reduz a eles. Enquanto a matemática informativa se prende ao conhecimento pronto e acabado, a formativa tem a ver com o processo de construção do conhecimento, com o fazer matemática. Nesse sentido, a matemática formativa se preocupa com o cultivo de atitudes matemáticas, tais como: estabelecer relações entre objetos matemáticos e formular conjecturas, testá-las e prová-las, se for o caso.

\section{AVALIAR EM MATEMÁTICA}

Acreditamos que poucos educadores e educandos têm consciência de que a avaliação é um processo contínuo e natural aos seres humanos, de que os homens se avaliam constantemente, nas mais diversas situações, diante da necessidade de tomar decisões, desde as mais simples até as mais complexas. A rotina da avaliação feita no dia-a-dia inicia-se pela verificação das informações sobre uma determinada situação, e, então, mediante a análise dessas informações, é tomada uma decisão.

Um exemplo bem simples desse procedimento é fornecido por Paulo Freire, em entrevista (gravada) concedida ao VIII Congresso Internacional de Educação Matemática. Ao argumentar sobre a necessidade de os homens se conscientizarem da existência de uma forma matemática de se estar no mundo, diz:

Quando a gente desperta, já caminhando para o banheiro, a gente já começa a fazer cálculos matemáticos. Quando a gente olha o relógio, por exemplo, a gente já estabelece a quantidade de minutos que a gente tem para, se acordou mais cedo, se acordou mais tarde, para saber exatamente a hora em que vai chegar à cozinha, que vai tomar o café da manhã, a hora que vai chegar o carro que vai nos levar ao seminário, para chegar às oito. Quer dizer, ao despertar os primeiros movimentos, lá dentro do quarto, são movimentos matematicizados. (apud D'Ambrosio, 2004)

$\mathrm{Na}$ prática pedagógica da matemática, a avaliação tem, tradicionalmente, se centrado nos conhecimentos específicos e na contagem de erros. É uma avaliação somativa, que não só seleciona os estudantes, 
mas os compara entre si e os destina a um determinado lugar numérico em função das notas obtidas.

Porém, mesmo quando se trata da avaliação informativa, é possível ir além da resposta final, superando, de certa forma, a lógica estrita e cega do "certo ou errado". Para que a avaliação da matemática informativa extrapole o lugar comum da classificação por notas, e surja como estratégia para a orientação da prática pedagógica, ela deve levar em conta os principais elementos envolvidos no processo de ensinar/aprender - o aluno, o professor e o saber -, possibilitando que tanto o professor como o aluno tenham um indicativo de como este está se relacionando com o saber matemático. Para isso, o aluno deve ser sujeito no processo de avaliação e não apenas o objeto a ser avaliado. Embora este procedimento seja visto por alguns como algo muito complicado, pode ser introduzido no cotidiano escolar sem grandes alterações da prática pedagógica do professor. Dentre as muitas possibilidades de alcançar tal objetivo, uma delas é considerar os erros dos alunos.

Encarados com naturalidade e racionalmente tratados, os erros passam a ter importância pedagógica, assumindo um papel profundamente construtivo, e servindo não para produzir no aluno um sentimento de fracasso, mas para possibilitar-lhe um instrumento de compreensão de si próprio, uma motivação para superar suas dificuldades e uma atitude positiva para o seu futuro pessoal. É por isso que Vergani (1993, p. 152) afirma: "interessar-se pelo aluno é interessar-se pelos seus erros". Assim, os erros não podem ser apenas assinalados, mas devem ser objeto de um trabalho específico do professor com o estudante.

Mesmo numa avaliação tradicional, na qual é solicitada ao aluno apenas a resolução de exercícios, é possível avançar para além da resposta final, considerando:

- o modo como o aluno interpretou sua resolução para dar a resposta;

- as escolhas feitas por ele para desincumbir-se de sua tarefa;

- os conhecimentos matemáticos que utilizou;

- se utilizou ou não a matemática apresentada nas aulas; $e$

- sua capacidade de comunicar-se matematicamente, oralmente ou por escrito. (Buriasco, 2004)

Se o professor levar em consideração esses itens na verificação da aprendizagem, ele vai alterar profundamente a qualidade de sua avaliação, promovendo significativas mudanças no processo de ensinar/aprender, mesmo sem modificar radicalmente a forma como atua em sala de aula. 
Por outro lado, a matemática formativa, por se referir essencialmente à estruturação do pensamento e à agilização do raciocínio, está umbilicalmente ligada ao fazer matemática e, portanto, mais próxima dos processos utilizados pelo matemático profissional. Um processo de ensinar/aprender com essa finalidade deve ter como inspiração o trabalho realizado pelos matemáticos e se caracterizar por

- partir de situações-problema internas ou externas à matemática;

- analisar as situações;

- pesquisar acerca de conhecimentos que possam auxiliar na solução dos problemas;

- elaborar conjecturas, fazer afirmações sobre elas e testá-las;

- refinar as conjecturas;

- perseverar na busca de soluções, mesmo diante de dificuldades;

- sistematizar o conhecimento construído a partir da solução encontrada, generalizando, abstraindo e desvinculando-o de todas as condições particulares;

- submeter os resultados obtidos à comunidade, utilizando, para isso, uma linguagem adequada; e

- argumentar a favor ou contra os resultados.

São essas as atitudes que devem ser cultivadas pelo aluno, sob a orientação do professor, quando se pensa em matemática formativa.

A avaliação em matemática, sob essa perspectiva, deve se preocupar fundamentalmente com essas atitudes, as quais só podem ser detectadas mediante a observação atenta, pelo professor, de seus alunos, enquanto realizam as tarefas que lhes foram determinadas. Esse acompanhamento deve ser conduzido de modo seletivo, de maneira que a atenção do professor recaia sobre um aluno ou grupo de alunos de cada vez. Como se trata de observar atitudes, o professor não pode assumir uma postura passiva; ao contrário, deve dialogar com os alunos para melhor compreender seus processos de pensamento e intervir quando necessário.

É preciso reconhecer, contudo, que o professor deve selecionar, dentre as informações captadas, apenas o que é realmente importante, de modo que essa atividade não o impeça de executar outras tarefas didáticas. Para isso, existem indicadores que, segundo Vergani (1993, p.155), podem nortear a observação pelo professor, entre os quais poderiam ser citados:

- o interesse com que o aluno se entrega às atividades matemáticas;

- a confiança que tem em suas possibilidades; 
- sua perseverança, apesar das dificuldades encontradas;

- se formula hipóteses, sugere idéias, explora novas pistas de pesquisa;

- se avalia criteriosamente a adequação do processo que adotou ou a solução que encontrou;

- se reflete sobre a maneira de planificar uma atividade e de organizar o seu trabalho;

- se pede ajuda em caso de dúvida ou de falta de conhecimentos; e

- se comunica suas dificuldades e descobertas aos colegas, de maneira adequada.

No entanto, para que essas atitudes possam ser cultivadas pelo aluno, a prática pedagógica não pode mais se centrar na exposição e reprodução de conteúdos que só privilegiam a memorização e não o desenvolvimento do pensamento.

A Educação Matemática, a partir de diversos estudos e pesquisas acerca desta questão, recomenda algumas estratégias para a consecução do fundamental e complexo processo de cultivar atitudes matemáticas nos alunos, ao mesmo tempo em que favorecem o desenvolvimento do seu pensamento. Dentre essas estratégias, ou "caminhos para se fazer matemática" em sala de aula, as mais indicadas para alcançar esse objetivo são a resolução de problemas, as investigações matemáticas em sala de aula e o uso de jogos.

\section{CONCLUSÃO}

Mesmo quando se trata de avaliar em matemática - uma área considerada, muitas vezes, árida e distante das questões sociais e políticas -, os processos avaliativos não estão dissociados da subjetividade pessoal, uma vez que cada um de nós, professores, desenvolve formas de avaliação concordes com suas opiniões intelectuais, suas atitudes sociais, seus referenciais teórico-metodológicos. Mais do que nas demais escolhas que fazemos referentes ao processo de ensino/aprendizagem, é na forma como concebemos a avaliação que se manifestam, mais claramente, as posições sociais e políticas que assumimos, consciente ou inconscientemente.

A trajetória que percorremos neste texto mostra, de forma cristalina, que nosso posicionamento sobre o que avaliar em matemática decorre de nossas convicções teóricas a respeito da matemática, da matemática escolar e do papel desse conhecimento na vida dos indivíduos. Enfim, mais do que 
estabelecer critérios, nossos sentimentos e convicções a respeito do que é avaliar em matemática podem ser sintetizados na frase de Guignard (1988) avaliar é deixar-se surpreender.

\section{REFERÊNCIAS BIBLIOGRÁFICAS}

BROUSSEAU, G. Os diferentes papéis do professor. In: PARRA, C.; SAIZ, I. Didática da matemática: reflexões psicopedagógicas. Trad. Juan A. Llorens. Porto Alegre: Artes Médicas, 1996.

BURIASCO, R. L. C. de. Análise da produção escrita: a busca do conhecimento escondido. In: ROMANOWSKI, J. P.; MARTINS, P. L. O.; JUNQUEIRA, S. R. A. (orgs.) Conhecimento local e conhecimento universal: a aula, aulas nas ciências naturais e exatas, aulas nas letras e nas artes. Curitiba: Champagnat, 2004.

CARAÇA, B. de J. Conceitos fundamentais da matemática. 9. ed. Lisboa: Sá da Costa Editores, 1989.

D’AMBRÓSIO, U. Por que se ensina matemática? Texto de curso a distância, promovido pela SBEM. Disponível em: www.sbem.com.br. Acesso em: 24 mar. 2004.

DAVIS, P. J.; HERSH, R. A experiência matemática. Rio de Janeiro: Francisco Alves, 1985.

FREUDENTHAL, H. Major problems of mathematics education. Educational Studies in Mathematics, n. 12, p. 133-155, 1981.

GONZALEZ, F. E. Paradigmas en la enseñanza de la matemática: fundamentos epistemológicos y psicológicos. Caracas: FEDUPEL, 1997.

GUIGNARD, N. Si l'erreur m'etait contée: essai crtitique des évaluations et étude de quelques rapports entre apprentissage, recherche et évaluation. Genève: Service de la Recherche Pédagogique, 1988.

KUHN, T. La estructura de las revoluciones científicas. México: Fondo de Cultura Económica, 1981. 
NOGUEIRA, C. M. I. História das idéias matemáticas: origens, fundamentos e futuro. Universidade Estadual de Maringá/Programa de Pós-graduação em Educação para a Ciência e o Ensino da Matemática, 2004. Apontamentos de aula.

PAVANELLO, R. M. Matemática e educação matemática. Boletim da SBEM - SP, n. 1, p. 4-14, 1993.

SANTALÓ, L. A. Matemática para não-matemáticos. In: PARRA, C.; SAIZ, I. (orgs.) Didática da matemática: reflexões psicopedagógicas. Trad. Juan A. Llorens. Porto Alegre: Artes Médicas, 1996.

VERGANI, T. Um horizonte de possíveis: sobre uma educação matemática viva e globalizante. Lisboa: Universidade Aberta, 1993.

ZABALA, A. A prática educativa: como ensinar. Trad. Ernani. F. da F. Rosa. Porto Alegre: Artmed, 1998.

Recebido em: outubro 2005

Aprovado para publicação em: novembro 2005 
